\title{
Wishful thinking in the prediction of competitive outcomes
}

\author{
Paul C. Price, California State University, Fresno, USA
}

\begin{abstract}
In each of two experiments, college students were assigned to two ad hoc groups (Team A and Team B) that competed in a dart-throwing contest. On each trial, one contestant from each team threw a single dart at a standard dart board, trying to come as close as possible to hitting the bull's-eye. Also on each trial, the other participants judged the likelihood that both the Team A contestant and the Team B contestant would come closer to hitting the bull's-eye. In both experiments $(N=36$ in Experiment $1 ; N=35$ in Experiment 2), participants exhibited a strong wishful thinking effect. They judged the likelihood that their own team members would come closer to be greater than the likelihood that the opposing team members would come closer. Experiment 2 suggested that it was participants' desires, as opposed to some other variable associated with team membership, that influenced their predictions. Experiment 2 also showed that the size of the effect did not depend on whether participants believed that their predictions had been influenced by their team membership. These results help bridge the gap between previous experimental laboratory studies, which have produced inconsistent results, and correlational field studies of sports fans and voters, which have consistently produced large effects.
\end{abstract}

People often engage in motivated reasoning, drawing conclusions that are consistent with their desires precisely because those conclusions are consistent with their desires (Kruglanski, 1996; Kunda, 1990). Experimental research, in which people's desires are manipulated in various ways, has demonstrated motivated reasoning effects on people's self-characterisations, beliefs about others, evaluations of scientific research, and many other kinds of judgement (see Kunda, 1990, for a review). For example, college students who are led to believe that being extroverted is positively related to academic achievement judge

This research was supported in part by a grant from the Decision, Risk, and Management Science Program, National Science Foundation. I also thank Jennifer Braunstein, Kim Khoo, Leah Mancuso, and Karla Spain for their help in collecting the data. 
themselves to be more extroverted than college students who are led to believe that introversion is positively related to academic achievement (Kunda \& Sanitioso, 1989). Although Taylor and Brown (1988) have suggested that such "positive illusions" are essential to good mental health, it seems likely that in some cases they lead to relatively poor decisions and the misdirected allocation of resources (e.g., when scientists or policy makers pursue or support discredited research because of its consistency with their desires). For both of these reasons, it is important to understand such effects.

There is, however, an important domain in which motivated reasoning effects have been inconsistent, and sometimes weak or nonexistent: predicting future outcomes. The possibility of such effects is of special interest to researchers concerned with human judgement and decision making because many important decisions are based in part on predictions of future outcomes. The decision whether to have surgery, for example, hinges on one's predictions about the success or failure of the surgery and its potential effects. It is especially important, therefore, to clarify whether, and under what conditions, motivated reasoning affects people's predictions of the future.

Early experimental research on this issue seemed quite convincing. For example, Marks (1951) demonstrated strong effects of children's desires on their predictions of whether they would draw a marked card from a shuffled deck containing a specified proportion of marked cards. On some trials, participants were told that they would win one point if they drew a marked card; on other trials, they were told that they would lose one point if they drew a marked card. When the proportion of marked cards in the deck was .50, participants stated that they expected to draw a marked card roughly $85 \%$ of the time when they stood to win a point and roughly $15 \%$ of the time when they stood to lose a point. These results were later replicated and extended using adult participants, small incentives for accuracy, and slightly different tasks by Irwin and his colleagues (Irwin, 1953; Irwin \& Graae, 1968; Irwin \& Metzger, 1966; Irwin \& Snodgrass, 1966; see also Crandall, Solomon, \& Kellaway, 1955; Pruitt \& Hoge, 1965). Although these effects were not always very strong, it seemed that a wishful thinking effect on people's predictions was well established.

However, some peculiarities of the Marks-Irwin experimental paradigm have recently raised the question of whether such effects are likely to be widespread. First, the laboratory prediction tasks used were highly artificial, and participants were given very little information on which to base their predictions. It could be that people base their predictions on their desires under these conditions for lack of any interesting alternative approaches. In fact, participants may have been aware that they were making predictions based on their desires as a simple way to complete a relatively uninteresting experimental task. Second, participants in these studies almost always made deterministic predictions, judging whether or not the target event would occur, as opposed to probabilistic predictions, judging the likelihood that the target event would occur. For this reason, it remains 
unclear whether their desires influenced their perception of the likelihood of the target event or whether it simply influenced their willingness to report "yes, it will happen" versus "no, it will not".

More recent efforts-designed in part to overcome these problems-have been less successful at demonstrating a wishful thinking effect on people's predictions. In an article descriptively titled "The elusive wishful thinking effect", Bar-Hillel and Budescu (1995) failed to find any convincing evidence of wishful thinking in a series of carefully conducted laboratory experiments. In some of Bar-Hillel and Budescu's experiments, participants made predictions about simple aleatory events, as in the earlier research. In others, they made predictions about more complex events, including weekly changes in the Dow Jones Industrial Average. In addition, Bar-Hillel and Budescu's participants made probabilistic predictions rather than deterministic ones. In only one condition of one experiment did these researchers find even the slightest evidence of a wishful thinking effect (see also Yates, Cole, \& Rodgers, 1989).

Also in recent years, however, correlational field studies - primarily of sports fans and voters in political elections-have consistently demonstrated strong relationships between people's desires and predictions (Babad, 1995; Babad, Hills, \& O'Driscoll, 1992; Babad \& Katz, 1991; Babad \& Yacobos, 1993; Buckley \& Sniezek, 1992; Fischer \& Budeseu, 1995; Granberg \& Brent, 1983; Granberg \& Holmberg, 1988; Price, 1997; Uhlaner \& Grofman, 1986). For example, Babad and Katz (1992) found a strong relationship between which soccer team in a professional match was favoured by fans and which team they predicted would win the match. Furthermore, the strength of this relationship did not depend on whether or not participants were warned not to let their desires affect their predictions. It also did not depend on whether they were attending the game or were at an off-site betting station actually making monetary bets on the outcome. Price (1997) has found an equally strong desire-prediction relationship among fans making probabilistic predictions of the outcome of an American college football game.

This raises the question of why it has been relatively difficult to demonstrate reliable wishful thinking effects in the laboratory but relatively easy to demonstrate strong desire-prediction correlations outside the laboratory. One possibility is that the effects of people's desires on their predictions could be relatively weak, as argued by Bar-Hillel and Budeseu (1995), and the results of the correlational field studies are due to other processes. For example, Fischer and Budescu (1995) have interpreted the desire-prediction correlation among Israeli voters as a result of selective social interaction. People interact primarily with others who share their political views, which gives them a distorted sense of the likelihood that their preferred candidates will be elected (see also Uhlaner \& Grofman, 1986).

Another possibility is that it is difficult to manipulate people's desires effectively in the laboratory. Whereas sports fans and voters can be expected to 
have strong desires that their teams or candidates prevail, participants in laboratory experiments may not care very much whether or not they earn or lose points, or even a few dollars, in a laboratory prediction task. This implies that a more effective manipulation of people's desires might produce reliable wishful thinking effects in the laboratory, which was the goal of the present study. The specific approach taken here was to create a laboratory analogue of the typical correlational field study, in which participants make predictions about the outcome of a competition between two social groups. To the extent that this results in a strong wishful thinking effect on people's predictions, it can be concluded that part of the difficulty in experimentally producing them in the laboratory is due to the relatively ineffective desirability manipulations used in previous research.

\section{EXPERIMENT 1}

Experiment 1 was an experimental laboratory study of wishful thinking that preserved some potentially important features of the typical correlational field study. Again, the typical correlational field study involves either sports fans predicting the outcome of a game or voters predicting the outcome of a political election. In both cases, the outcome being predicted is the result of a competition between two opposing social groups (sports teams or political parties). Presumably, one's desire that one team or candidate win, as opposed to the other, stems primarily from one's affiliation with that team or candidate. It was hypothesised that creating a similar situation in the laboratory would allow for the effective manipulation of people's desires and, therefore, produce large wishful thinking effects on people's predictions.

Additional support for this hypothesis comes from social psychological research demonstrating consistently large effects of group affiliation on resource allocation decisions and various kinds of social judgement (Messick \& Mackie, 1989). It has typically been assumed that belonging to a group motivates people to treat in-group members preferentially and perceive them in a positive light, perhaps as a means of enhancing their own self-esteem (Tajfel, 1981; Tajfel \& Turner, 1986). In fact, such effects have often been observed immediately after participants have been assigned to ad hoc groups based on some arbitrarily chosen variable (e.g., a food preference) or even at random. This procedure has come to be called the minimal group paradigm (Tajfel, 1972; Turner, 1975, 1999).

In essence, then, Experiment 1 was a minimal group study in which the dependent variable was a prediction about the outcome of a competition between the groups. Specifically, participants were randomly assigned to two teams, which then competed in a dart-throwing contest. On each trial, one contestant from each team threw a dart at a standard dart board, each one trying to come 
closer to hitting the bull's-eye. Also on each trial, the rest of the participants judged the likelihood that each contestant would come closer to hitting the bull'seye. If participants engage in wishful thinking, then members of both teams should judge it to be relatively more likely that their own team-mates will come closer to hitting the bull's-eye.

\section{Method}

Participants. A total of 36 undergraduate students at California State University, Fresno, participated as an introductory psychology course requirement.

Design and procedure. During each of the two experimental sessions, 18 participants were randomly assigned to one of two teams. The first participant to arrive at the classroom where the experiment took place was assigned to Team A and seated on the left side of the room, the second was assigned to Team B and seated on the right side, the third was assigned to Team A, and so on. Thus, participants who knew each other and arrived together were probably assigned to different teams. A standard set of instructions explaining what was to happenand which called attention to the fact that participants had been assigned to teams - was read to the entire group.

During the first part of the procedure, a randomly selected participant from each team came to the front of the room and threw a single dart at a standard dart board, trying to hit the bull's-eye, from a distance of about 2.5 metres. The Team A contestant always threw his or her dart first. This process was repeated until all members of both teams had thrown one dart. During this part of the experiment, participants were instructed simply to watch the others throw their darts and to form impressions of their dart-throwing ability. During the second part of the experiment, this process was repeated with different randomly selected pairs of contestants. In addition, for each pair of contestants, the rest of the participants judged the likelihood that each contestant would come closer to hitting the bull'seye. Their likelihood judgements took the form of percentages from $0 \%$ to $100 \%$, such that the two judgements for a pair of contestants had to sum to $100 \%$. For example, for one pair of contestants, a participant might judge the likelihood that the Team A contestant would come closer to the bull's-eye to be $60 \%$ and the likelihood that the Team B contestant would come closer to the bull's-eye to be $40 \%$. Each participant wrote all of his or her judgements on a single sheet of paper that was collected immediately at the end of the experiment. Because there were nine pairs of contestants in each experimental session, and because participants did not judge their own likelihood of coming closer to the bull's-eye, each participant made eight pairs of likelihood judgements. 


\section{Results and discussion}

For each participant, the mean judgement of the likelihood that the Team A contestant would come closer to the bull's-eye was computed. Therefore, if wishful thinking occurred, Team A members' judgements should tend to be higher than Team B members' judgements. Furthermore, if the two teams were roughly equally matched in terms of their apparent dart-throwing ability, Team A members' judgements should tend to be greater than 50\% while Team B members' judgements should tend to be less than $50 \%$. This is precisely what happened. In the first session, the mean judgement of Team A members was $53.26(S D=3.84)$ and the mean judgement of Team B members was $42.86(S D=$ 6.26). In the second session, the mean judgement of Team A members was 50.28 $(S D=7.02)$ and the mean judgement of Team B members was $45.93(S D=8.42)$. An analysis of variance (ANOVA) with team membership and session as between-subjects factors confirmed that there was a main effect of team membership, $F(1,32)=11.25, p<.05$. There was no main effect of session, $F(1,32)=0.00$, n.s., and no team-by-session interaction, $F(1,32)=1.90$, n.s. The $F$ value of 0.00 for the main effect of session reflects the fact that the mean judgement for the two sessions, averaged across the two teams, was nearly identical: 48.06 in the first session and 48.10 in the second.

These results seem to confirm that participants' desires can influence their predictions. In fact, as in correlational research on desirability bias in the prediction of sporting event outcomes and political elections, the effect of team affiliation was quite strong. The difference between the mean likelihood judgements of Team A members and Team B members was approximately one standard deviation, an effect size that Cohen (1962) has characterized as "large" for the behavioural sciences. These results have two clear implications. The first is that the wishful thinking effect is not necessarily elusive, given an effective desirability manipulation (cf. Bar-Hillel \& Budescu, 1995). The second is that the desire-prediction correlations observed in field studies of sports fans and voters probably do reflect wishful thinking to some extent (as opposed to, for example, selective social interaction).

There are, however, two related problems with Experiment 1. Although it was meant to isolate the effects of people's desires on their predictions, Experiment 1 included no manipulation check to confirm that assigning people to different teams had the intended effect on their desires. In addition, even if people's desires were successfully manipulated, the effect on their predictions could be due to some other variable associated with team membership. For example, there might be a simple position preference, such that participants are biased in favour of people sitting or standing near them, regardless of whether they desire that those people come closer to hitting the bull's-eye. These problems were addressed in Experiment 2. 


\section{EXPERIMENT 2}

Experiment 2 was a replication of Experiment 1, but with two important additions. First, at the end of the experiment, participants rated the strength of their desire that their team members come closer to hitting the bull's-eye. This served two purposes. It served as a manipulation check to confirm that assigning participants to different teams did, in fact, affect their desires in the intended way. It also allowed for an analysis of the effects of participants' desires on their predictions independent of their team membership. The wishful thinking hypothesis implies that participants' desires should be strongly associated with their predictions, but that their team membership per se should not be strongly associated with their predictions. On the other hand, if the important causal variable is not participants' desires, but rather some other variable associated with team membership, then team membership should be strongly associated with their predictions, but their desires should not. The second addition to Experiment 2 was asking participants whether they believed that their predictions had been influenced by their team membership. For both theoretical and practical reasons, it would be useful to know whether people are aware of engaging in wishful thinking (Siepmann, 1999). For example, if people are aware of their wishful thinking, then simply warning them about it might be an effective debiasing technique. If they are not aware of it, then other techniques would probably be necessary.

\section{Method}

Participants. A total of 35 undergraduate students at California State University, Fresno, participated as part of an introductory psychology course requirement.

Design and procedure. Again, during each of two experimental sessions, participants were randomly assigned to two teams. Because, in the second session, there were nine members on one team and eight on the other, participants made judgements for eight pairs of contestants rather than nine in this session. The rest of the design and procedure of Experiment 2 were the same as those of Experiment 1, but with the following additions. After participants had made all of their likelihood judgements, they completed a written questionnaire that asked them first to rate the strength of their desire that their team members come closer to the bull's-eye, and next to indicate whether they thought their predictions had been influenced by their team membership. They made their desire ratings by agreeing with one of four sentences: (1) I did not care who came closer to the bull's-eye, (2) I had a slight desire that my team members come closer to the bull's-eye, (3) I had a moderate desire that my team members come closer to the 
bull's-eye, or (4) I had a strong desire that my team members come closer to the bull's-eye. They indicated whether they thought their predictions had been influenced by their team membership by agreeing with one of two sentences:(1) My predictions were not influenced by which team I was on, or (2) My predictions were influenced by which team I was on.

\section{Results and discussion}

Assigning participants to teams appears to have affected their desires. After coding the four desire statements as $0-3$, the overall mean desire rating was computed to be $1.80(S D=1.02)$, which is reasonably close to a "moderate desire" that a participant's own team members come closer to hitting the bull's-eye. Of the 35 participants, $32(91 \%)$ indicated that they had at least a slight desire. At the same time, most participants reported that their team membership (and by implication their desire) did not affect their predictions. Of the 35 participants, $26(74 \%)$ indicated that they did not believe that their predictions were affected by their team membership. Of course, among those who did not believe that their predictions were affected by their team membership were the three participants who indicated that they did not care which team members came closer to hitting the bull's-eye. Caution should be used in interpreting these results, however, because participants' self-reports might have been influenced by social desirability or other demand characteristics.

In addition, participants' desires again influenced their predictions. In the first session, the mean judgement of Team A members was $55.61(S D=8.53)$ and the mean judgement of Team B members was $52.89(S D=11.64)$. Note that both teams in this session exhibited a tendency to believe that Team A members would come closer to hitting the bull's-eye than Team B members. This may reflect better performance by Team A members on the practice trials, or it may indicate that Team A members appeared for some reason to be better dart-throwers (e.g., they appeared more athletic). Nevertheless, the mean judgement of Team A members was still greater than that of Team B members, indicating wishful thinking. In the second session, the mean judgement of Team A members was $53.61(S D=8.59)$ and the mean judgement of Team B members was $44.17(S D=$ 8.39). This time, the ANOVA included as an additional between-subjects factor participants' beliefs about the influence of their team membership on their predictions. Again, there was a statistically significant main effect of team membership, $F(1,27)=5.32, p<.05$, and there were no effects either of session, $F(1,27)=1.98$, n.s., or of team-by-session interaction, $F(1,27)=0.20$, n.s. In addition, there was no main effect of participants' beliefs about the influence of their team membership, $F(1,27)=0.06$, n.s. In other words, the wishful thinking effect was equally strong whether or not participants believed that their predictions had been influenced by their team membership.

The experimental design and preceding analyses suggest an effect of team 
membership on participants' predictions. In addition, the manipulation check suggests an effect of team membership on participants' desires. It is not yet completely clear, however, that participants' desires-as opposed to some other variable associated with team membership - was the key causal factor. For this reason, a multiple-regression analysis was conducted with team membership, session, and desire as independent variables and the mean likelihood judgement for the Team A contestant as the dependent variable. For this analysis, the desire ratings of Team $B$ members were coded as negative to produce a set of desire ratings that ranged from -3 (strong desire that the Team $\mathrm{B}$ members come closer to hitting the bull's-eye) to +3 (strong desire that the Team A members come closer to hitting the bull's-eye). The rationale for this analysis is that if desire is the key causal factor, then it should emerge as a statistically significant predictor of participants' likelihood judgements when the effects of team membership per se are controlled for. The results of this analysis are presented in Table 1. Note that the only statistically significant predictor of participants' likelihood judgements was their desires. Team membership per se was not a statistically significant predictor. This is precisely what one would expect if participants' desires, rather than some other variable associated with team membership, were affecting their predictions.

\section{GENERAL DISCUSSION}

The two experiments reported here revealed large wishful thinking effects on people's predictions of competitive outcomes in a laboratory setting. These results help to bridge the gap between those of previous laboratory experiments on wishful thinking, which have produced inconsistent (sometimes null) effects, and those of correlational field studies, which have consistently produced large effects. What the present experiments and the correlational field studies have in common is that participants' desires were induced by their group affiliations. It

TABLE 1

Regression analysis results for Experiment 2

\begin{tabular}{lcccc}
\hline Source & $\begin{array}{c}\text { Unstandardised } \\
\text { regression } \\
\text { coefficient }\end{array}$ & $\begin{array}{c}\text { Standard } \\
\text { error }\end{array}$ & $\begin{array}{c}\text { Standardised } \\
\text { regression } \\
\text { coefficient }\end{array}$ & $t$ \\
\hline Constant & 55.42 & 15.05 & & $3.68^{*}$ \\
Team & 9.14 & 6.73 & 0.46 & 1.36 \\
Session & -4.41 & 2.98 & -0.22 & 0.15 \\
Desire & 4.28 & 1.69 & 0.86 & $2.53^{*}$ \\
\hline
\end{tabular}

Effects of team membership, session, and desire on mean judgements of the likelihood that the Team A contestant would come closer to hitting the bull's-eye.

$t$ values denoted by an asterisk are statistically significant at the .05 level. 
seems reasonable to suppose that such desires are stronger, or perhaps different in kind, from the desires induced in previous laboratory experiments by offering participants at most small monetary gains and losses. Does this mean that wishful thinking effects on people's predictions occur only under a fairly restrictive set of conditions and that they are not likely to be widespread? On the contrary, many important outcomes about which people make predictions are desirable or undesirable precisely because of their relevance to the social groups to which they belong. Thus, predictions about outcomes relevant to people's own families, schools, countries, and so forth may be especially likely to be affected by wishful thinking.

An important, and as yet unanswered, question concerns how people's desires influence their predictions. In discussing motivated reasoning more generally, both Kruglanski (1996) and Kunda (1990) have argued that people's desires affect the way they search for and process information, and that the conclusions they reach are the result of this biased information processing. Likewise, Bar-Hillel and Budeseu (1995) suggest that wishful thinking about the future, when it does occur, involves biased recall of information. For example, a sports fan might predict that his team will win the championship game because he tends to recall information suggesting his team will win and tends not to recall information suggesting his team will lose. It seems premature, however, to rule out the possibility that the effect of people's desires on their predictions can be more direct than this. In the present experiments, participants had relatively little information to recall or process in making their predictions, and they made them relatively quickly. It does not seem unreasonable, therefore, to hypothesise that people's desires may have influenced their predictions without any significant mediating processes.

Another important issue concerns people's awareness of their wishful thinking. In the present experiments, most participants reported that they did not believe that their predictions were influenced by their team membership. Nevertheless, their predictions were affected to the same degree as those of participants who did believe that their predictions were influenced by their team membership. It is interesting to compare these results to those of Siepmann (1999), who found that most of his subjects seemed to believe that their desires influenced their predictions. In one of his studies, subjects judged the likelihood that various desirable and undesirable events would occur. Then they were asked what judgements they would have made had they been thinking in an ideal way. Most subjects made ideal judgements that differed in desire-related ways from their initial judgements. However, many subjects' ideal judgements were less positively correlated with their desires than were their initial judgements (indicating a belief that they had been engaging in wishful thinking), but many other subjects' ideal judgements were more positively correlated with their desires than were their initial judgements (indicating a belief that they had been engaging in pessimistic thinking). In another study, Siepmann showed that 
subject's beliefs about whether they had been engaging in wishful thinking were only weakly related to their objective tendency to overpredict positive outcomes relative to negative outcomes. It appears, therefore, that people can hold different beliefs about the influence of their desires on their predictions. Some may believe that their desires have no influence, others believe their desires have a positive influence, and still others believe their desires have a negative influence. It is not clear yet, however, what determines the beliefs people hold or the extent to which those beliefs are accurate.

The present research implies quite strongly that people do engage in wishful thinking about future outcomes. Additional research is needed, however, to understand the basic psychological processes involved and how those processes interact with various situational factors and individual differences to determine people's predictions. Unfortunately, it appears that these interactions are likely to be complex. For example, people who accurately believe that they engage in wishful thinking may spontaneously avoid it or compensate for it when the stakes are high (e.g., when predicting the outcome of a surgery), and therefore make accurate predictions. People who inaccurately believe that they do not engage in wishful thinking may fail to avoid it or compensate for it even when they are warned about it and the stakes are high, and therefore make inaccurate predictions. Understanding these complexities is an important task for judgement and decision researchers.

\section{REFERENCES}

Babad, E. (1995). Can accurate knowledge reduce wishful thinking in voters' predictions of election outcomes? The Journal of Psychology, 129, 285-300.

Babad, E., Hills, M., \& O'Driscoll, M. (1992). Factors influencing wishful thinking and predictions of election outcomes. Basic and Applied Social Psychology, 13, 461-476.

Babad, E., \& Katz, Y. (1991). Wishful thinking-Against all odds. Journal of Applied Social Psychology, 21, 1921-1938.

Babad, E., \& Yacobos, E. (1993). Wish and reality in voters' predictions of election outcomes. Political Psychology, 14, 37-54.

Bar-Hillel, M., \& Budescu, D. (1995). The elusive wishful thinking effect. Thinking and Reasoning, 1, 71-103.

Buckley, T., \& Sniezek, J. (1992). Passion, preference, and predictability in judgmental forecasting. Psychological Reports, 70, 1022.

Cohen, J.D. (1962). The statistical power of abnormal-social psychological research: A review. Journal of Abnormal and Social Psychology, 65, 145-153.

Crandall, V.J., Solomon, D., \& Kellaway, R. (1955). Expectancy statements and decision times as functions of objective probabilities and reinforcement values. Journal of Personality, 24, 192 203.

Fischer, I., \& Budescu, D. (1995). Desirability and hindsight biases in predicting results of a multiparty election. In J.-P. Caverni, M. Bar-Hillel, F.H. Barron, \& H. Jungermann (Eds.), Contributions to decision making - I (pp. 193-211). Amsterdam: Elsevier. 
Granberg, D., \& Brent, E. (1983). When prophecy bends: The preference-expectation link in the U.S. presidential elections, 1952-1980. Journal of Personality and Social Psychology, 45, 477-491.

Granberg, D., \& Holmberg, S. (1988). The political system matters: Social psychology and voting behavior in Sweden and the United States. Cambridge: Cambridge University Press.

Irwin, F.W. (1953). Stated expectations as functions of probability and desirability of outcome. Journal of Personality, 21, 329-335.

Irwin, F.W., \& Graae, C.N. (1968). Tests of the discontinuity hypothesis of the effects of independent outcome values upon bets. Journal of Experimental Psychology, 76, 444-449.

Irwin, F.W., \& Metzger, M.J. (1966). Effects of probabilistic independent outcomes upon predictions. Psychonomic Science, 5, 79-80.

Irwin, F.W., \& Snodgrass, J.G. (1966). Effects of independent and dependent outcome values upon bets. Journal of Experimental Psychology, 71, 282-285.

Kruglanski, A.W. (1996). Motivated social cognition: Principles of the interface. In E.T. Higgins \& A.W. Kruglanski (Eds.), Social psychology: Handbook of basic principles (pp. 493-520). New

York: Guilford Press.

Kunda, Z. (1990). The case for motivated reasoning. Psychological Bulletin, 108, 480-498. Kunda, Z.,

\& Sanitioso, R. (1989). Motivated changes in the self-concept. Journal of Experimental Social Psychology, 25, 272-285.

Marks, R.W. (1951). The effect of probability, desirability, and "privilege" on the stated expectations of children. Journal of Personality, 19, 332-351.

Messick, D.M., \& Mackie, D.M. (1989). Intergroup relations. Annual Review of Psychology, 40, 45-81.

Price, P.C. (1 997, November). Sports fans' wishful thinking is reduced by a relative-frequency elicitation question. Poster presented at the meeting of the Society for Judgment and Decision

Making, Philadelphia, PA.

Pruitt, D.G., \& Hoge, R.D. (1965). Strength of the relationship between the value of an event and its subjective probability as a function of method of measurement. Journal of Experimental Psychology, 69, 483-489.

Siepmann, M. (1999). Disbelieved beliefs: Subjective estimates of bias in probabilistic beliefs and their relationships to desire. Unpublished doctoral dissertation, University of Pennsylvania.

Tajfel, H. (1981). Human groups and social categories. Cambridge: Cambridge University Press.

Tajfel, H., \& Turner, J.C. (1986). The social identity theory of intergroup behavior. In S. Worchel \& W.G. Austin (Eds.), Psychology of intergroup relations (pp. 7-24). Chicago: Nelson-Hall.

Taylor, S.E., \& Brown, J.D. (1988). Illusion and well-being: A social psychological perspective on mental health. Psychological Bulletin, 103, 193-210.

Turner, J.C. (1975). Social comparison and social identity: Some prospects for intergroup behaviour. European Journal of Social Psychology, 5, 149-178.

Turner, J.C. (1996). Henri Tajfel: An introduction. In P. Robinson (Ed.), Social groups and identities: Developing the legacy of Henri Tajfel (pp. 1-24). Oxford: Butterworth/Heinemann.

Uhlaner, C.J., \& Grofman, B. (1986). The race may be close but my horse is going to win: Wish fulfillment in the 1980 presidential election. Political Behavior, 8, 101-129.

Yates, J.F., Cole, L.G., \& Rodgers, W. (1989, November). Value biasing in probability judgment. Paper presented at the meeting of the Psychonomic Society, Irvine, CA. 